\title{
A laboratory cage for foster nursing newborn mice
}

S. Marques-de-Araújo ${ }^{1}$ and M.A. Cardoso ${ }^{2}$ 15etor de Parasitologia Básica and 'Biotério,

Universidade Estadual de Maringá, Maringá, PR, Brasil

\section{Correspondence}

S. Marques-de-Araújo

Setor de Parasitologia Básica, DAC

Universidade Estadual de Maringá

Av. Colombo, 5790, Zona 7

87020-900 Maringá, PR

Brasil

Fax: + 55-44-263-7440

E-mail: marqueslima@wnet.com.br

Received January 6, 1998

Accepted November 26, 1998

\section{Abstract}

We describe a cage to be used for foster nursing in order to guarantee that original mother's colostrum is not ingested by the newborn mice. A common $(30.5 \mathrm{~cm} \times 19.5 \mathrm{~cm} \times 12.0 \mathrm{~cm})$ mouse cage was fitted with a wire net tray with a mesh $(1 \mathrm{~cm} \times 1 \mathrm{~cm})$, which divides the cage into an upper and a lower compartment. Mice born to females placed in the upper compartment pass through the mesh and fall into the lower compartment, where another lactating female with one or two of its own pups are. Of a total of 28 newborn mice of $\mathrm{C} 3 \mathrm{H} / \mathrm{He}$ and Swiss strains, 23 were successfully fostered. Important observations are presented to show that this is a valuable alternative for foster studies without great suffering on the part of the female.

Maternal influences are very important in determining immune responsiveness and resistance to infection. Several studies that discuss the fetal-maternal relationship stress the importance of breast feeding for the transfer of immunological proteins and the transmission of pathogens to the newborn. Rodents have long been used as models for studying maternal-fetal immune interaction (1). In mice, this interaction is mediated by the transfer of immunoglobulins present in mother's milk (2).

Although foster nursing techniques are crucial to the development of this research area, they are not easily achieved. Certain mouse strains are more aggressive, so cannibalism is more frequently observed. Likewise, in some experimental settings the manipulation of the animal is more stressful, causing some difficulties in foster experiments. Several investigators (3-7) use the adoptive breast feeding approach to study the fetal-maternal relationship. The intrinsic difficulties of this kind of approach are related to technical problems. Although solutions have been developed for this problem, many of them have not been published. The manipulation of newborn animals of all species requires special care even in safe environments, free from stressful factors or intermittent infections. Some papers $(8,9)$ discuss the use of aromatic plants that are rubbed on the gloves to mask the human scent, avoiding this indicator of human manipulation of the newborns and consequent killing by their mothers. Surgery for the removal of unborn mouse pups or protection of the nipples with adhesive tape surely prevent colostrum ingestion by the newborn. However, these methods can cause suffering or even death of the dams.

We described here the construction of a 
Figure 1 - Schematic illustration of a laboratory cage for fostering newborn mice. A, Water bottles. The water bottle which supplies water to the animals in compartment $\mathrm{C}$ must have a smaller and straight sipper. The one to be used by the animals placed in compartment $D$ must have a longer sipper tube, slightly bent, in order to pass through the wire mesh of compartment C. B, Top of a common cage where water bottles and food must be placed. The division in the top of the cage that prevents water and food from mixing must be removed in order to better place the two water bottles and food pellets. C, Upper compartment used to house the pregnant female. It is made of the upper half of an ordinary plastic cage to which the wire net (mesh: $1 \times 1$ $\mathrm{cm}$ ) is adapted. The dimensions are $30.5 \mathrm{~cm} \times 19.5 \mathrm{~cm} \times 7.0 \mathrm{~cm}$. $D$, Lower compartment where the foster mother must be placed. Food pellets should be placed in one of its corners. The dimensions are $30.5 \mathrm{~cm} \times 19.5$ $\mathrm{cm} \times 12.0 \mathrm{~cm}$. Since the upper compartment is inserted into the lower one, the true useful dimensions are $30.5 \mathrm{~cm} \times 19.5 \mathrm{~cm}$ $x 8.0 \mathrm{~cm}$.

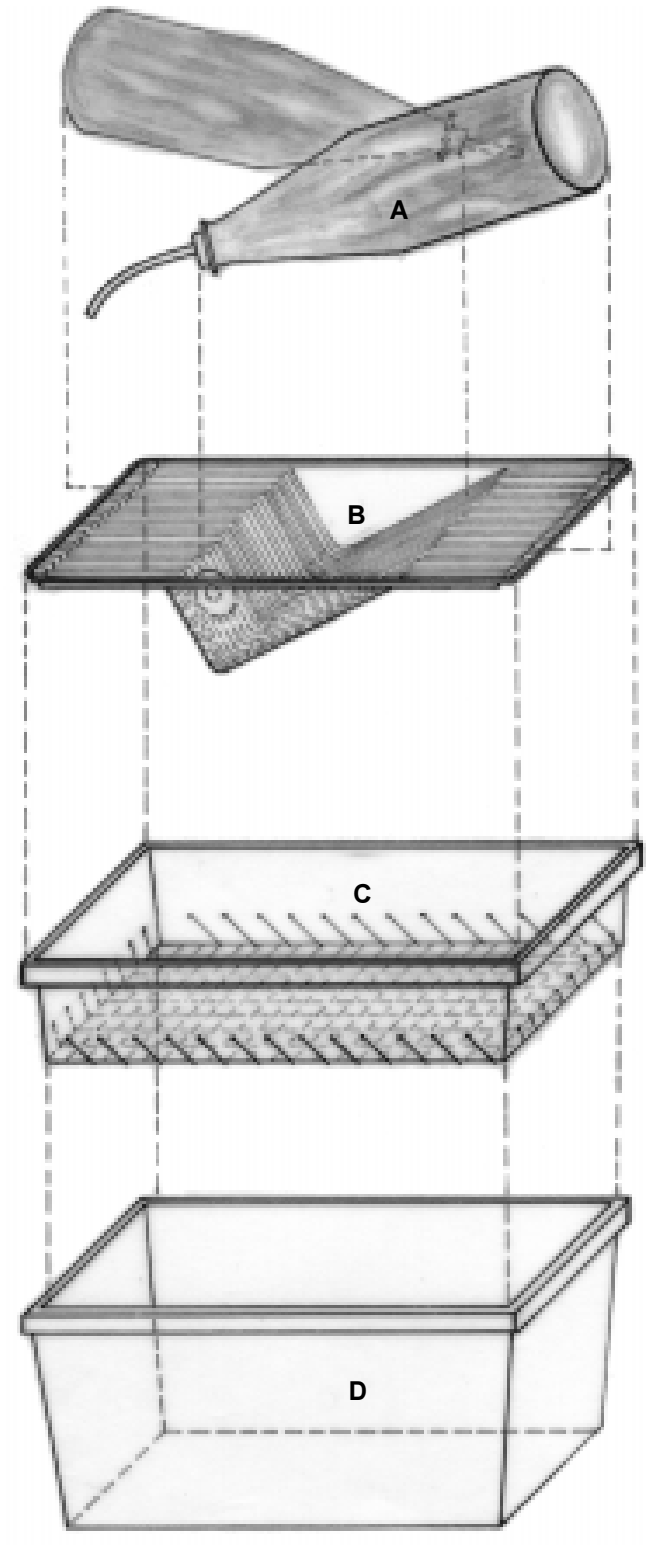

cage to solve many of the difficulties found in foster nursing (Figure 1). A common mouse cage was fitted with a wire net tray with a mesh $(1 \mathrm{~cm} \mathrm{x} 1 \mathrm{~cm})$, which divides the cage into an upper and a lower compartment. Mice born to females placed in the upper compartment (Figure 1C) pass through the mesh and fall into the lower compartment (Figure 1D), where another lactating female with one or two of its own pups has been placed. This allows a significant lower rate of newborn mortality and higher rate of foster mothering acceptance. Using this cage we were able to cause offspring born to chagasic mothers to be fostered by noninfected mothers and vice-versa. More importantly, we were sure that no pup ever ingested the colostrum of its original mother. Table 1 shows the results observed. It should be pointed out that the bottom of the $\mathrm{C}$ compartment is a wire net and a pregnant female placed there is prevented from developing her natural behavior of nest preparation. Since we adapted a regular laboratory cage, compartments $\mathrm{C}$ and $\mathrm{D}$ were greatly reduced. Nevertheless, of a total of 28 mice born, 23 were successfully fostered. We document here the use of this cage with two mice strains (Table 1).

It is important to point out that room temperature should be maintained at $21-24^{\circ} \mathrm{C}$. Water and food pellets must be independently available in the upper (C) and lower compartments (D). In the lower compartment food pellets must be placed in a corner. The division in the top of the cage that prevents water and food from mixing must be removed in order to better place the two water bottles and food pellets. The water bottle which supplies water to the animals in the upper compartment is a common one with a smaller and straight sipper. The one to be used by the animals in the lower compartment must have a longer sipper tube, slightly bent, in order to pass through the wire mesh of compartment $\mathrm{C}$. The dimensions of the wire mesh must be adapted for each mouse 
strain. The mesh should be as small as possible because the females become highly stressed when their pups fall down to the lower compartment, consequently trying to pass through the wire mesh to rescue them. To minimize the uncomfortable period in this cage, mice must be placed in each compartment as close to parturition as possible. Experience in mouse manipulation and vaginal plug examination (10) help determining when delivery is about to happen. Immediately after the offspring is born the upper compartment must be removed. The litter of the foster mother should be no more than 4 days older than the adopted pups, because the older ones will crowd out the younger pups as they compete for milk. A few pups from the original litter may be kept with the foster mother but they must be first distinguished from the adopted ones by ear or tail clipping.

In the sixth edition of The UFAW Handbook on the Care and Management of Laboratory Animals (1987) (11) the editor states that a pair of breeding mice and their litter
Table 1 - Experimental results obtained using the fostering cage and T. cruzi-infected (TC) or non-infected (C) C3H/He females or non-infected Swiss females (C).

aExperiment done in order to determine the ideal mesh dimensions. The pups were returned to their original mother; bthe original mother was greatly stressed trying to pass through the mesh and was returned to her pups; 'the foster mother was very aggressive and bit the original mother's foot; dthe delivery was not monitored.

\begin{tabular}{llccc} 
Foster mother & Original mother & \multicolumn{3}{c}{ Adopted pups } \\
\cline { 3 - 5 } & & Born & Dead & Alive \\
\hline C3H/He-M91C & C3H/He-M 91C & 4 & 0 & $4^{\mathrm{a}}$ \\
C3H/He-M 36C & C3H/He-M29TC + M38TC & 7 & 2 & 5 \\
Swiss-M 1C & C3H/He-M29TC & - & - & $-\mathrm{b}$ \\
Swiss-M2C & C3H/He-M 30TC & 3 & 1 & 2 \\
Swiss-M3C & C3H/He-M 38TC & 3 & 0 & $3^{c}$ \\
Swiss-M4C & C3H/He-M29TC & 5 & 1 & 4 \\
C3H/He-M38TC & C3H/He-M27C + M52C & 6 & 1 & 5 \\
C3H/He-M30TC & C3H/He-M27C + M52C & $?$ & $?$ & $4^{d}$
\end{tabular}

can be kept in a cage about $14 \mathrm{~cm}$ wide, 30 $\mathrm{cm}$ long and 12 to 15 deep. Using our cage as a suggestion, a modified one can be built using dimensions recommended for mouse cages $(11,12)$, providing a useful tool for fostering studies.

\section{References}

1. Head J R (1991). Rodent matemal-fetal immune interactions. Current Opinion in Immunology, 3: 767-771.

2. Simister NE (1990). Transport of monomeric antibodies across epitelia. In: Metzger $\mathrm{H}$ (Editor), Fc Receptors and the Action of Antibodies. American Society for Microbiology, Washington, DC, 57-73.

3. Kolodny MH (1939). The transmission of immunity in experimental trypanosomiasis (T. cruzi) from mother rats to their offspring. American J ournal of Hygiene, 30: 19-39.

4. Kresina TF \& Nisonoff A (1983). Passive transfer of the idiotypically suppressed state by serum from suppressed mice and transfer of suppression from mothers to offspring. J ournal of Experimental Medicine, 157: 15-21.
5. Olson J C \& Leslie GA (1981). Inheritance patterns of idiotype expression: maternalfetal immune regulatory networks. Immunogenetics, 13: 39-56.

6. Carlier Y, Rivera MT, Truyens C, Ontivero M, Flament J , Van Marck E \& Maertelaer $\checkmark$ (1992). Chagas' disease: decreased resistance to Trypanosoma cruzi acquired infection in offspring of infected mice. American J oumal of Tropical Medicine and Hygiene, 46: 116-122.

7. Yamaguchi $N$, Shimizu S, Hara $A \&$ Saito $T$ (1983). The effect of maternal antigenic stimulation upon the active immune responsiveness of their offspring. Immunology, 50: 229-238.

8. Ferrer J \& Valle J (1973). El Arte de Criar Conejos y Otros Animales de Pelo. 4th edn. Editorial Aedos, Barcelona, Espanha.
9. Cross J W (1975). Cria y Explotacion de los Conejos. 5th edn. Ediciones Gea, Barcelona, Espanha.

10. Carlier Y, Rivera MT, Truyens $C$, Puissant F \& Milaire J (1987). Interactions between chronic murine Trypanosoma cruzi infection and pregnancy: fetal growth retardation. American J ournal of Tropical Medicine and Hygiene, 37: 534-540.

11. Cunliffe-Beamer TL \& Les EP (1987). The laboratory mouse. In: Poole Trevor B (Editor), The UFAW Handbook on the Care and Management of Laboratory Animals. 6 th edn. Longman Scientific \& Technical, Essex, 275-308.

12. Luca RR, Alexandre SR, Marques T, Souza $\mathrm{NL}$, Merusse J LB \& Neves SP (Editors) (1996). Manual para Técnicos em Bioterismo. Winner Graph, São Paulo. 